\title{
VARIATION IN ASTIGMATISM FOLLOWING THE SINGLE-STEP, SELF-SEALING CLEAR CORNEAL SECTION FOR PHACOEMULSIFICATION
}

\author{
S. RAUZ, A. REYNOLDS, H. W. A. HENDERSON and N. JOSHI \\ London
}

\begin{abstract}
SUMMARY
Purpose: A single-step, self-sealing, $3.2 \mathrm{~mm}$ clear corneal section is described and the incidence and variation of surgically induced astigmatism following phacoemulsification over a period of 3 months is determined.

Methods: Twenty-two patients who underwent uncomplicated $3.2 \mathrm{~mm}$ clear corneal phacoemulsification with foldable Allergan silicone intraocular lens implantation were autorefracted pre-operatively and on day 1 , week 1 , week 6 and at 3 months. The variation in induced astigmatism was analysed using the subtraction method and vector analysis. The change in direction of the cylindrical axis was examined.

Results: The induced astigmatism represented by the total vector on day 1 was $1.17 \mathrm{D}$ and vector decomposition ratio, ATR:WTR (against-the-rule:with-therule), was 21.05:78.95. The total vector increased by $0.5 \mathrm{D}$ in the first week and then stabilised. Vector decomposition showed an against-the-rule astigmatic drift so that by 3 months the ATR:WTR was 40.49:59.91. There was a tendency of the axis of the negative cylinder to swing towards the corneal section meridian on day 1 and to oscillate around that meridian at week 1 and week 6 . By 3 months the direction reverted to that pre-operatively, in most cases.

Conclusions: The single-step, self-sealing clear corneal section is mechanically stable and, though there is some variability in the measured astigmatism, there is an acceptable functional result throughout the post-operative period.
\end{abstract}

The use of sutures and the size and position of the incision are parameters that are known to cause surgically induced astigmatism following cataract surgery. The introduction of foldable intraocular

From: Department of Ophthalmology, Charing Cross Hospital, London, UK.

Correspondence to: Miss Saaeha Rauz, Birmingham and Midland Eye Centre, City Hospital NHS Trust, Dudley Road, Birmingham B18 7QU, UK. Tel: +44 (0121)-544-3801. lenses has facilitated a reduction in incision size during phacoemulsification, thereby dispensing with the need for sutures. The initial incision may be scleral or corneal. We describe a single-step, selfsealing, clear corneal stab incision and look at the variation in astigmatism during the first 3 months post-operatively following phacoemulsification.

\section{METHOD}

The Nidek AR-1000 autorefractor was used to obtain an objective measure of the refractive cylinder in 22 patients pre-operatively. A single-step, self-sealing clear corneal section was fashioned using a $3.2 \mathrm{~mm}$ keratome. The entry site was positioned $1 \mathrm{~mm}$ anterior to the limbus at the $105^{\circ}$ meridian (Fig. 1). The keratome was angled at approximately $27^{\circ}$ and advanced through the cornea so that the tunnel created was approximately $2 \mathrm{~mm}$ in length. All patients then underwent routine phacoemulsification with foldable silicone intraocular lens implantation (Allergan) under peribulbar local anaesthesia performed by the same surgeon (N.J.). All had subconjunctival betamethasone $4 \mathrm{mg}$ and tobramycin $20 \mathrm{mg}$ at the end of their surgery. At first dressing, unaided Snellen visual acuities, autorefraction and intraocular pressures were recorded. A Seidel's test was performed using $2 \%$ fluorescein to assess aqueous leakage from the corneal section. Autorefraction and visual acuities were repeated at week 1 , week 6 and 3 months following surgery. All patients had post-operative g. dexamethasone $0.1 \%$ and g. chloramphenicol $0.5 \%$ four times a day for the first week; these were reduced over the ensuing 3 weeks. Patients excluded from the series were those who had had previous intraocular surgery, uveitis and glaucoma.

\section{RESULTS}

Of the 22 patients who participated in this study, 12 were women and 10 were men. Thirteen were 

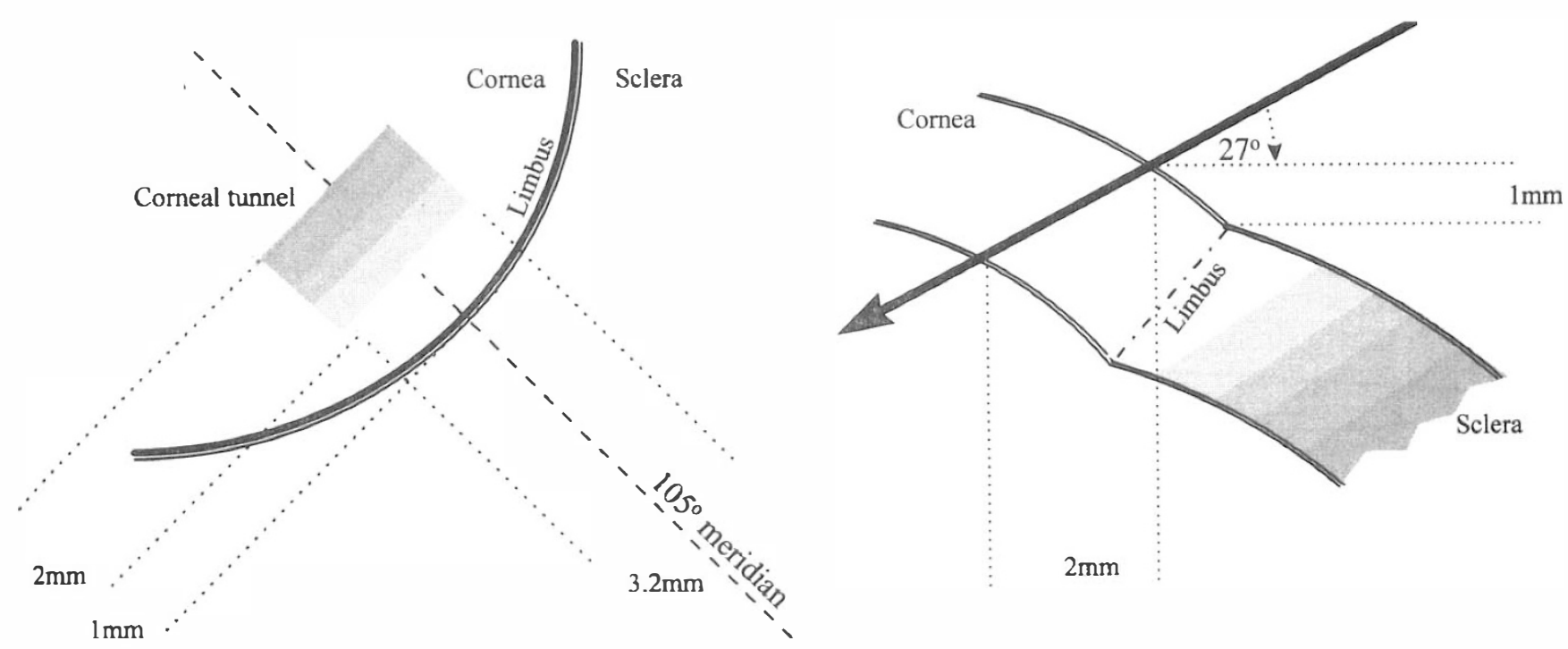

Fig. 1. The single-step, self-sealing, clear corneal incision.

(a) Surgeon's view of the cornea and the section. (b) Crosssectional view of the tunnel. See text for details.

Caucasian in origin, 4 Afro-Caribbean, 3 Asian and 2 Chinese. The average age was 74.68 years (range $61-90$ years). The mean phacoemulsification duration was 3.46 minutes (range 1.6-6.7 minutes) and power range was $40-80 \%$.

The entry sites of all the corneal incisions were found to be well apposed and there was no evidence of aqueous leak. All patients were found to be normotensive (mean $17 \mathrm{mmHg}$ : range $11-20 \mathrm{mmHg}$ ). Snellen visual acuities are found in Fig. 2. The induced astigmatism as represented by the total vector and the subtraction method are shown in Fig. 3. Vector decomposition is illustrated in Fig. 4. It was observed that there was a tendency for the axis of the negative cylinder to swing towards the corneal section on day 1 and to oscillate around that meridian on week 1 and week 6. By 3 months, however, the axis reverted to its original direction in most cases.

\section{DISCUSSION}

The last decade has brought about a change in the role of the cataract surgeon, from merely extracting an opaque human lens and replacing it with a clear synthetic intraocular lens, to considering the refractive aspects of the surgery. An incision in any tissue causes it to gape. Using the cornea as an example, the section causes flattening along the meridian of the incision and steepening $90^{\circ}$ away, i.e. against-thewound astigmatic drift. The degree to which this phenomenon occurs will be dependent on the incision parameters such as site, length, configuration and healing. The longer the incision, the larger the wound gape, and the greater the corneal flattening,

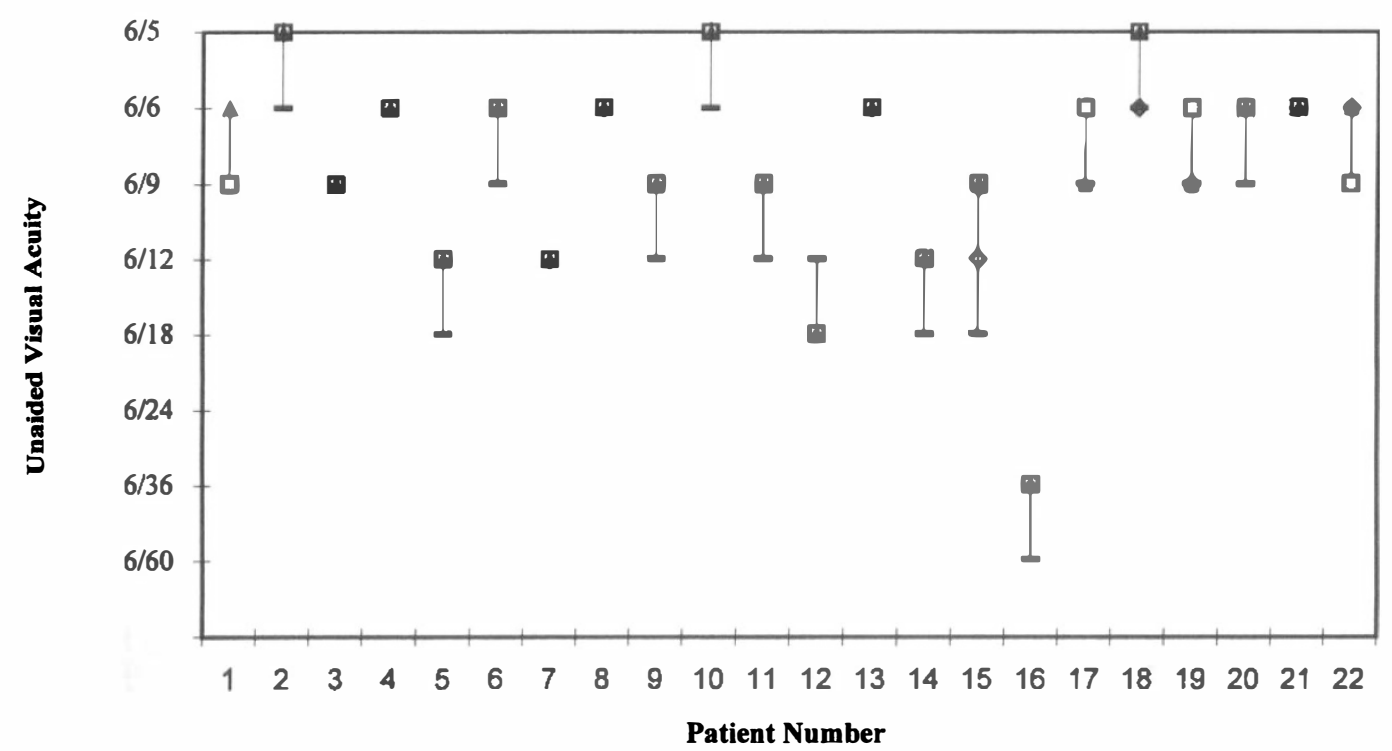

- day1
○week 1
qweek 6
$\triangle 3$ months

Fig. 2. Variation in Snellen visual acuity. 


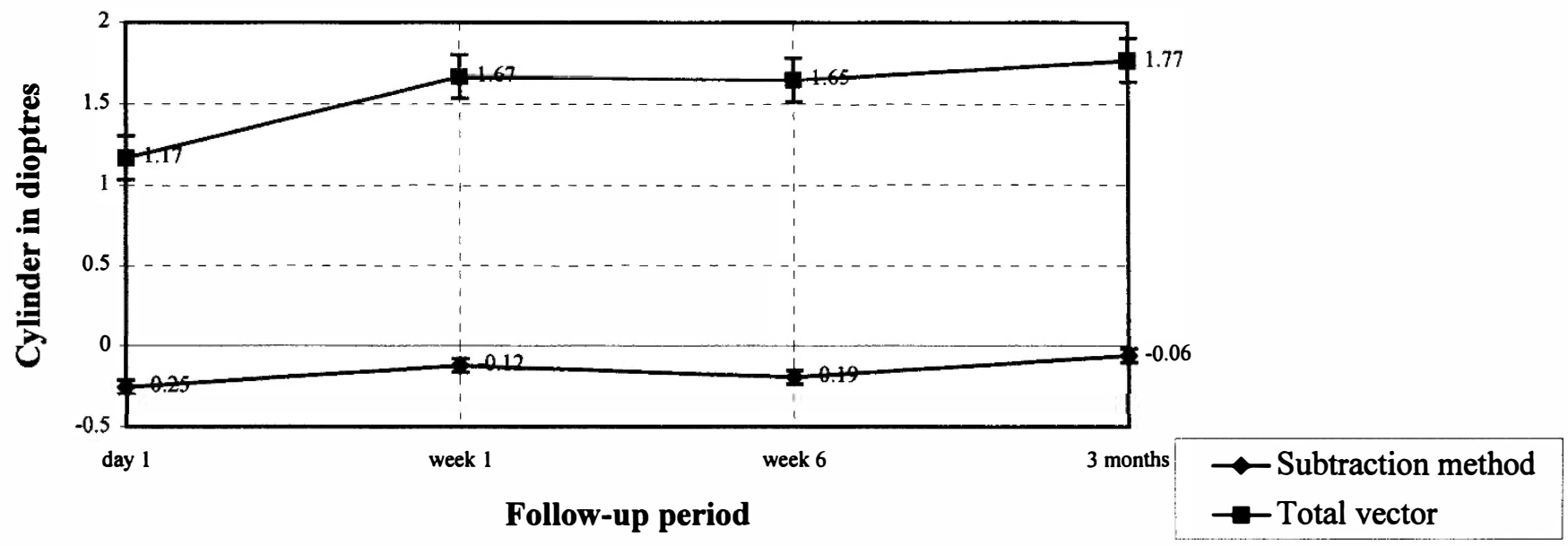

Fig. 3. Induced astigmatism as represented by the total vector and the subtraction method.

thereby delaying the healing process and prolonging the visual recovery. Assessing these changes may be difficult. The commonly used subtraction method only takes account of changes which occur in the magnitude of the cylinder disregarding any changes in axis. For example, in our results the maximum median induced astigmatism is $0.25 \mathrm{D}$ for the entire follow-up period. Vector analysis, as the name suggests, takes account of both magnitude and direction. The total value may be broken down into two components, i.e. vector decomposition into withthe-rule (WTR) and against-the-rule (ATR). Though this is a rather simplistic representation of the complex changes which occur on the contour of the corneal dome, the method is useful in quantifying these changes. A comparison of the two analytical methods is shown in Fig. 3, highlighting that the results from the subtraction method may be misleading.

The Nidek AR-1000 autorefractor was used to obtain an objective measure of the astigmatism by recording the refractive cylinder. The results using this autorefractor have been compared with those from subjective refraction and have been found to correspond to the spherical equivalent; there, is a high percentage of agreement for both the spherical or cylindrical components. ${ }^{1}$ In addition the visual acuity obtained by the autorefraction corresponded well with that obtained by subjective refraction. The results of our study show that the single-step, selfsealing $3.2 \mathrm{~mm}$ clear corneal section induces a total vector cylinder of $1.17 \mathrm{D}$ on the first post-operative day that increases by $0.5 \mathrm{D}$ during the next week, remaining stable thereafter, varying only $0.1 \mathrm{D}$. Vector decomposition shows that the ATR:WTR ratio is $21.05: 78.95$ on day 1 (Fig. 4). Over the first 6 weeks there is an against-the-rule astigmatic drift and by 3 months the ATR:WTR ratio has nearly equalised, being slightly weighted towards the WTR vector (40.49:59.51). Clinical studies have shown a small incision such as the $3.2 \mathrm{~mm}$ incision to be astigmatically stable, ${ }^{2-7}$ and despite some

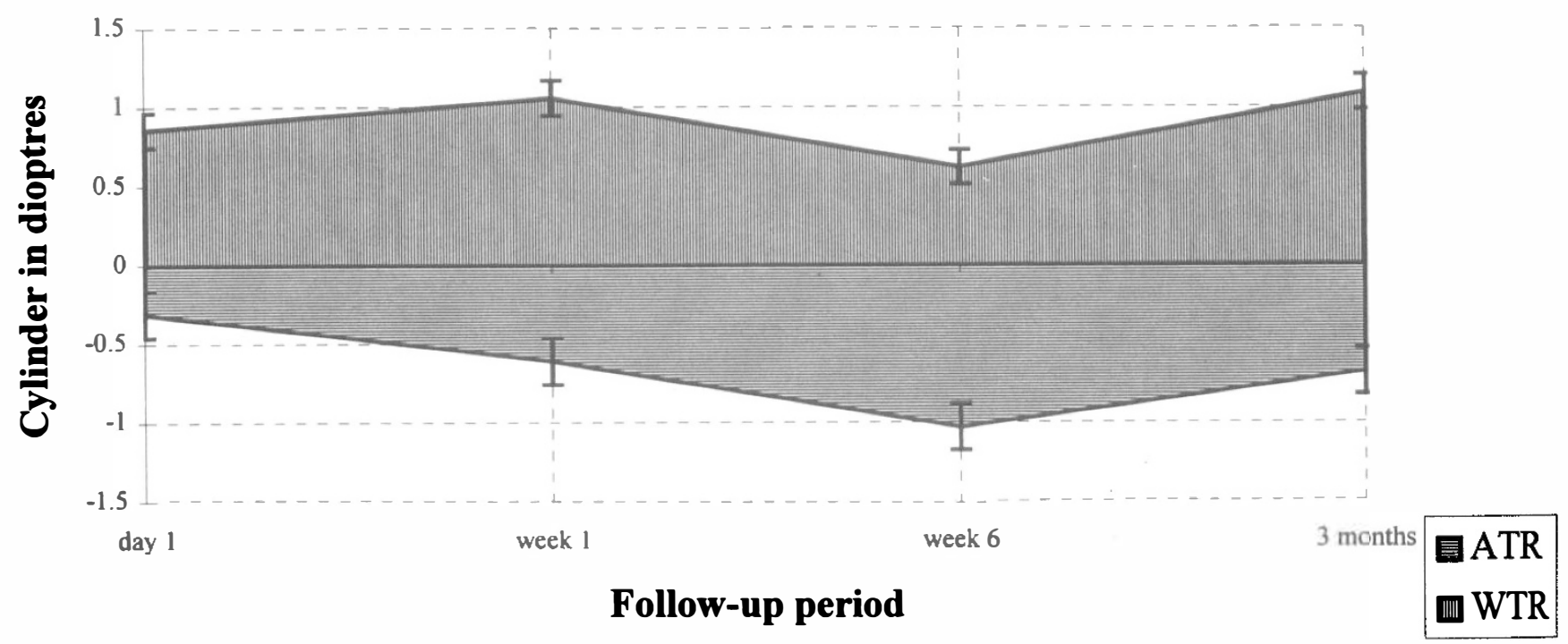

Fig. 4. Change in induced astigmatism by vector decomposition. ATR, againsi-the-rule. WTR, with-the-rule. 
Table I. Section position, strength and astigmatism

\begin{tabular}{l|ll}
\hline & Wound strength & Against-the-wound astigmatism \\
\hline $\begin{array}{l}\text { Least } \\
\text { Intermediate }\end{array}$ & $\begin{array}{l}\text { superior, corneal } \\
\text { superior, scleral and temporal, corneal } \\
\text { temporal, scleral }\end{array}$ & $\begin{array}{l}\text { temporal, scleral or corneal } \\
\text { superotemporal, scleral or corneal } \\
\text { superior, scleral or corneal }\end{array}$ \\
\hline
\end{tabular}

variability in our results, especially on day 1 , postoperative visual function was favourable.

There have, however, been several studies looking at the relative mechanical stability of clear corneal incisions in cadaver eyes. The clear corneal, bevelled incision constructed anterior to the limbus is shown to resist external pressure applied, due to support from the adjacent limbal structures, provided the length of the incision is kept below $3 \mathrm{~mm} .{ }^{8}$ Another study designed to examine the relative ability of clear corneal incisions to resist aqueous leakage and iris prolapse, concluded that the rectangular $3.2 \mathrm{~mm} \times$ $2.0 \mathrm{~mm}$ incision leaked and demonstrated iris prolapse at 13 pounds per square inch ( $\mathrm{psi}$ ) whilst square corneal wounds ranging from $1.0 \mathrm{~mm} \times 1.0 \mathrm{~mm}$ to $3.2 \mathrm{~mm} \times 3.2 \mathrm{~mm}$ withstood pressures of greater than 525 psi. $^{9}$ Clinically the larger $3.2 \mathrm{~mm}$ square wound would be impractical as it would encroach upon the visual axis, whilst the smaller wounds would be limited by technology and the physical size of the phaco tip. Despite this evidence from cadaver models our $3.2 \mathrm{~mm} \times 2.0 \mathrm{~mm}$ single-step, clear corneal incision proved to be self-sealing as none of our patients demonstrated aqueous leak or iris prolapse.

The site of the incision, however, will influence the direction of the cylinder. The healing of an incision placed at the $90^{\circ}$ meridian would be affected by the pull of the superior rectus muscle and that temporally by the lateral rectus muscle. In addition, the blinking mechanism will also disturb the wound, modifying the healing response and thus the astigmatism. Corneal and scleral sections have been shown to react differently to external mechanical stresses ${ }^{9,10}$ such as ocular motility and lid dynamics, affecting the eventual tensile strength and againstthe-wound astigmatic drift (Table I). ${ }^{9-13}$ The position and type of incision could be used to manipulate the axis of astigmatism. In our study, the corneal section was constructed around the $105^{\circ}$ meridian. This would explain the observed swing of the negative cylinder towards this meridian. This then appeared to oscillate around this meridian during the first 6 weeks. This change in the axis is to be expected. The position of the wound would be influenced by the action of the two adjacent recti muscles, i.e. the superior rectus and one of the horizontal recti (depending on which eye), explaining the oscillation around this meridian during the first 6 weeks. Being a small incision this disturbance was slight so that once the wound had stabilised at 3 months there was little change in most cases in the direction of the axis from that pre-operatively. There were, however, five exceptions all of which developed a net change of $35^{\circ}$ or more. The final direction of the axis in all these patients, except one, was towards that of the section. It has been demonstrated that there is an enlargement of the incision at each step of uncomplicated phacoemulsification surgery and irreversible stretching or tearing may occur, so that it is incorrect to assume that the initial keratome size equals the final incision size. ${ }^{14}$ It could be inferred that in some cases the incision enlarged excessively due to both intrinsic and extrinsic factors, thereby producing greater wound gape, causing the axis to be permanently diverted to this meridian whilst the wound itself remained self-sealing. These observed changes in the axis were not reflected in the vector analysis or visual acuities.

One patient was an exception to the general trend. The original direction of the axis of the negative cylinder was $101^{\circ}$. The surgery was complicated by difficulty retrieving the sub-incisional cortical lens matter, which was eventually left in situ. This resulted in severe post-operative inflammation necessitating intensive topical g. prednisolone acetate. The negative cylinder axis in this case swung almost $60^{\circ}$ away from that recorded at pre-admission to $160^{\circ}$. This unpredictable change was possibly a consequence of a combination of the extra manipulation needed during surgery, the post-operative inflammation and the use of intensive g. prednisolone acetate. Though there have been no studies confirming delayed corneal section healing by the use of topical steroids, it would be reasonable to propose that they must have some effect through their action on collagen synthesis. It is worth noting that this patient was also Afro-Caribbean in origin.

This study was designed to assess the variation in astigmatism produced by a single-step, self-sealing clear corneal section and its integrity following phacoemulsification with foldable intraocular lens implantation. We conclude that this incision is mechanically stable and though there is some variability in the measured astigmatism, there is an acceptable functional result throughout the postoperative period.

We would like to thank Don Andrews and Derek O'Driscoll for their help in the conduct of this study, and Paul B. Chell (Fellow, Moorfields Eye Hospital) for his invaluable help with the vector analysis.

Key words: Phacoemulsification, Sutureless, Astigmatism, Vector analysis. 


\section{REFERENCES}

1. Kinge B, Midelfart A, Jacobsen G. Clinical evaluation of the Allergan Humphrey 500 autorefractor and the Nidek AR-1000 autorefractor. Br J Ophthalmol 1996; 80:35-9.

2. Suzuki R, Kurimoto S. Similarities and differences between Kelman phacoemulsification and extracapsular cataract extraction procedures in the spontaneous regression of corneal astigmatism from against-the-rule astigmatism. Ophthalmic Res 1992;24:134-41.

3. Steinert RE, Brint SF, White SM, Fine IH. Astigmatism after small-incision cataract surgery: a prospective randomised multicentre comparison of 4- and $6.5-\mathrm{mm}$ incisions. Ophthalmology 1991;98:417-23.

4. Kohnen T, Dick B, Jacobi KW. Comparison of astigmatism after temporal clear corneal tunnel incisions of different sizes. J Cataract Refract Surg 1995;21:417-24.

5. Feil SH, Crandell AS, Olson RJ. Astigmatic decay following small incision, self-sealing cataract surgery: one year follow-up. J Cataract Refract Surg 1995; 21:433-6.

6. Hyashi K, Hyashi H, Nakao F, Hyashi F. The correlation between incision size and corneal shape changes in sutureless cataract surgery. Ophthalmology 1995;102:550-6.
7. Levy JH, Pisacano AM, Chadwick K. Astigmatic changes after cataract surgery with $5.1 \mathrm{~mm}$ and $3.5 \mathrm{~mm}$ sutureless incisions. J Cataract Refract Surg 1994;20:630-3.

8. Ernest PH, Fenzl R, Lavery KT, Sensoli A. Relative stability of clear corneal incisions in cadaver eye model. J Cataract Refract Surg 1995;21:39-42.

9. Ernest PH, Lavery KT, Kiessling LA. Relative strength of scleral corneal and clear corneal incisions constructed in cadaver eyes. J Cataract Refract Surg 1994; 20:626-7.

10. Anders N, Pham DT, Wollensak J. Wound strength in self-sealing cataract surgery depending on the site and depth of incision [in German]. Klin Monatsbl Augenheilkd 1995;206:442-5.

11. Kohnen T, Mann PM, Husain SE, Abarca A, Koch DD. Corneal topographic changes and induced astigmatism resulting from superior and temporal scleral pockets. Ophthalmic Surg Lasers 1996;27:263-9.

12. Kohnen T, Dick B. Computerised videokeratographic analysis of astigmatism induced by temporal corneal tunnel incision for phacoemulsification. Invest Ophthalmol Vis Sci 1994;35:1435.

13. Hyashi K, Nakao F, Hyashi F. Corneal topographical analysis of superolateral incision of cataract surgery. $\mathrm{J}$ Cataract Refract Surg 1994;20:392-9.

14. Steinert RF, Deacon J. Enlargement of incision width during phacoemulsification and folded intraocular lens surgery. Ophthalmology 1996;103:220-5. 